\title{
IMPLICAÇÕES, DESASSOSSEGOS E CRIAÇÃO NA ESCRITA ACADÊMICA ${ }^{1}$
}

Estela Scheinvar

Universidade do Estado do Rio de Janeiro - UERJ, Brasil

Katia Aguiar

Universidade Federal Fluminense - UFF, Brasil

Maria Lívia do Nascimento

Universidade Federal Fluminense - UFF, Brasil

\begin{abstract}
Resumo
A partir da nossa experiência como professoras universitárias propomos a ferramenta da análise de implicação para pensar a função normativa presente na prática da escrita no campo da educação. Entendemos este tipo de produção textual como parte de um projeto de disciplinarização da vida apoiado na produção científica como instauradora de uma racionalidade que reforça certas relações de saber-poder. Nos interessa operar pelo descentramento de uma estrutura como modo de autorregulação discursiva, em especial na universidade, incidindo nas relações de poder por alguns dispositivos analisadores. Ante rigidez, normas, controles, encontramos interlocução com autores que apostam numa escrita que inclua outros corpos, outras narrativas, outros mundos, numa atitude histórico-crítica radical. Com tais intercessores, o presente artigo busca, na problematização de modelos estabelecidos, expor suas incompletudes como condição para a escrita como atividade criadora.
\end{abstract}

Palavras-chave: Escrita Acadêmica; Análise de Implicação; Formação; Modos de Subjetivação.

\begin{abstract}
From our experience as university professors, we propose the implication analyses as a tool to think the normative function that is present in the writing practice, in the education field. We understand this kind of textual production as a part of the disciplinarization of life project, supported by scientific production in terms of the instauration of a rationality that reinforce certain relations of knowledge-power. We are interested to operate through the decentration of an structure as a discursive auto-regulation, especially in the university, incising in power relations using some analyzers devices. Facing rigidity, norms, controls, we find interlocution with authors that bet on a writing that includes other bodies, other narratives, other worlds, in a radical historical-critic attitude. With such intersections, the present article aims at - in the problematization of established models - exposing its incompleteness as a condition for writing as a creative activity.
\end{abstract}

Keywords: Academic Writing; Implication Analyses; Academic Education; Subjectivities Modes. 
Se eu tivesse de escrever um livro para comunicar o que já penso, antes de começar a escrevê-lo, não teria jamais a coragem de empreendê-lo.

Michel Foucault

\section{Algumas implicações em análise na escrita acadêmica}

O presente texto se tece como uma composição de ideias produzidas pela nossa prática como professoras-pesquisadoras em universidades públicas. Um texto-espaço para deixar fluir interrogações, apostas, angústias, celebrações, questionamentos, provocados, ao longo de muitos anos, por uma das atividades mais recorrentes na vida acadêmica. Convocamos, com estas análises, a pensar na escrita acadêmica como tema-problema, dizendo de alguns dos caminhos acionados em nossas conversações sobre a prática da escrita em diferentes situações e, portanto, em diferentes momentos de nossa vida profissional. Não se trata de uma conversa ou prática pessoal ou íntima, mas de um fazer do ofício que fala do coletivo, dos instituídos e de movimentos instituintes, em diálogo.

Reconhecida como uma atividade central nas ciências humanas e sociais, a escrita tornou-se uma atividade sacralizada. É no formato escrito que a maior parte da produção profissional ligada à formação e à vida acadêmica tem reconhecimento e prestígio. Outras linguagens, como a plástica, a musical, a corporal e a oral perdem espaço e até validade em algumas áreas, na institucionalização do trabalho realizado nas universidades e centros de pesquisa. Mais ainda, a própria escrita é validada desde que formatada no modelo instituído. Como declarou em um seminário na Universidade do Estado do Rio de Janeiro ${ }^{2}$ uma estudante do doutorado em antropologia, provinda de uma cultura indígena do centro-oeste brasileiro, a tese que realizava sobre seus costumes e tradições nativas em nada dialogaria com o seu povo, já que este não se comunica pela escrita. O modelo escrito como modo de produzir conhecimento prevalece a muitos outros objetivos declarados da produção acadêmica, como o de construir referências para dialogar com os grupos pesquisados e apoiálos.

A escrita é o meio pelo qual se consagra um saber científico em grande parte dos campos instituídos de produção de conhecimento, sem nos interrogarmos, como comunidade científica, as implicações do que fazemos com aquilo e aqueles que dizemos ser nosso objeto de trabalho. O que será um objeto de trabalho para nós? Apenas uma relação de certificação, por meio de certo tipo de escrita, que recusa pensar seus efeitos no processo de forma(ta)ção de novos acadêmicos? Quais nossas interrogações em relação ao uso que é dado ao que produzimos? De que modo nossa escrita se utiliza de pessoas e espaços pesquisados sem pensar, coletivamente, suas demandas e os efeitos do que produzimos sobre suas vidas?

Tais questionamentos nos convocam a colocar em análise nossas implicações como escritoras no ambiente universitário, trazendo para a narrativa nossas motivações éticas, políticas e sociais ao tomarmos o ato da escrita como uma prática histórica. Para tanto, nos 
apoiamos na afirmação que não existe neutralidade e, portanto, a produção de um texto envolve escolhas de dizeres e de diferentes modos de enunciar. Entretanto, se há um modo hegemônico para a escrita acadêmica, há tensões que modulam os desvios do escrever objetivado nas formas de um artigo, uma tese, um relatório de pesquisa. Nesses casos, o modo de escrita dá, ou não, credibilidade ao texto, ao pesquisador, ao autor, enfim, validando ou não uma narrativa. E há que referir os dois momentos em que isso ocorre. Tanto quando somos autoras avaliadas por pares, cuja função é rejeitar o texto que não se enquadra, quanto no contexto em que ocupamos o lugar de leitoras de teses, participamos de bancas examinadoras, emitimos pareceres, avaliamos produções. Nesses casos, também nós, de modo instituído, somos conduzidas a seguir os cânones e estranhamos o texto que escapa aos moldes.

Em nossa trajetória acadêmica tentamos resistir a essa armadilha por meio da análise de implicação de nossas práticas, ferramenta que permite a saída de territórios identitários, de conhecimentos específicos, cercados pelos limites disciplinares. Difícil, certamente, estar fora dos parâmetros sob os quais fomos sendo forma(ta)das. As tensões são muitas, mas o desafio está lançado provocando uma instigante relação mais aberta a interrogações que a respostas. A análise de implicação busca problematizar a produção de verdades presente nas práticas, possibilitando um estranhamento dos modelos hegemônicos historicamente construídos, apontando que a escrita não precisa estar necessariamente inscrita em uma fórmula.

Quando René Lourau e Georges Lapassade (1977) propõem a análise institucional, seus conceitos operatórios, para pensar a institucionalização das práticas sociais apresentam a análise de implicação como uma ferramenta central. Esses autores afirmam que colocar em análise a produção das verdades que se fazem presentes nas práticas e nos espaços por elas habitados, possibilita estranhamentos a modelos fortalecidos pela naturalização. Desse modo, criam-se condições para que uma prática, como por exemplo a da escrita acadêmica, problematize as diferentes instituições que a constituem e atravessam. Ou seja, a análise de implicação, como problematização, traz para o campo das forças os acontecimentos frequentemente desconsiderados, tidos como estranhos. Com isso, promove conexões até então inusitadas e recusa o lugar de neutralidade do pesquisador com o objeto que pesquisa, do profissional com a população por ele atendida, do autor da escrita acadêmica com a produção de saber que ele está construindo ao escrever. Tal ferramenta operatória que coloca em análise nossas implicações entende que ao explicitar, trazer para o campo presente as instituições que atravessam a pesquisa, a elaboração de um artigo, as definições que determinam a competência técnico-acadêmica são criadas possibilidades para a emergência de outros modos de atuação diferentes dos instituídos.

Desse modo, a análise de implicações se constitui como potente instrumento para interrogar a normalização. Entretanto, enquadrar-se na norma é a estratégia para sobreviver às demandas acadêmicas. E fica-se aprisionado ao instituído. Se não estou enquadrado, não sou um bom escritor. A isso Lourau (2004) refere como sobreimplicação, processo de aceitação das demandas e dos mandatos socais como aspectos naturais de qualquer profissão. Sobreimplicado no modo único de produção do saber acadêmico, o escritor abraça uma 
profissionalização da escrita com suas regras restritivas, regras de deontologia. Desse modo, pesa de maneira individual o reconhecimento ou não de suas produções. Sentindo-se dominado pela culpa, pela obrigação, temendo o insucesso, esse mergulho sobreimplicado nas práticas da escrita dita correta dificulta o processo da análise de implicação, visto que todo o campo permanece ocupado por um determinado e único objeto: o escrever normatizado.

A sobre implicação favorece processos de institucionalização de práticas. O modelo instituído de escrita produz diferentes efeitos, dentre eles o texto avaliado como inaceitável, por não compor com o modo enquadrado, e com isso fica de fora uma produção considerada menor pelas instituições científicas e editoriais. Há a escrita correta e há o fora texto, que passa a ocupar o lugar de uma produção não valorizada e até rejeitada. Questionando esses modelos de enquadramento e de exclusão de modos múltiplos de expressão escrita, como resistir a isso? Como resistir ao aprisionamento do instituído?

Deleuze (1997, p. 11) nos dá uma pista: "Escrever é um caso de devir, sempre inacabado, sempre em via de fazer-se, e que extravasa qualquer matéria vivível ou vivida. É um processo, ou seja, uma passagem de Vida que atravessa o vivível e o vivido". Em parceria com Deleuze (1998) cabe perguntar o que a insistente normalização da escrita acadêmica em seus arroubos de qualificação e classificação faz com os afetos e a possibilidade de criação na escrita. Ser criativo não é uma ordem a ser cumprida. Desde a introdução à linguagem escrita o pensar foi sendo atravessado por regras rígidas, como condição para a interlocução e uma boa qualificação tanto do texto quanto do processo de aprendizagem. Interrogar-se sobre os modos de pensar, de escrever, de se comunicar, no espaço acadêmico, é uma prática que atenta aos agenciamentos dos afetos. Ao contrário de pensar a escrita acadêmica como o preenchimento de formas/fôrmas em busca de uma verdade conclusiva, Nietzsche assume a produção textual como uma arma, "[...] porque cada livro é um escrito de combate" (NIETZSCHE, 2017, p. 4). Deixar fluir afetos que recusem enquadramentos implica no agenciamento de forças que requerem, como elementos fundamentais, a energia e a convicção para o bom combate; para o combate aos instituídos, mesmo quando eles não deixem de nos acompanhar, de preferência para instigar o desassossego.

A implicação como conceito-intercessor das análises abre para nós diferentes caminhos de combate aos instituídos fazendo surgir forças instituintes explicitando paradoxos, tensões e liberando potências criadoras na fruição imanente dos afetos. São apostas que instigam a contestação do que está estabelecido provocando desassossego, desestabilizações e a criação de outros possíveis.

\section{Escrita, jogos de poder e a produção do sujeito}

A disposição para colocar nossas práticas em análise, assumindo aquela dupla direção de enfrentamento e de criação, na contestação do que está estabelecido em nosso campo de ação como professoras, nos aproxima de contribuições filosóficas que tensionam a abordagem clássica que faz equivaler pensamento e razão. Em Deleuze (1988), o pensamento 
como atividade criadora quer desviar-se dos parâmetros colocados pela imagem dogmática (clássica) que define o que é pensar, submetendo-o a modelos e valores preestabelecidos, fortemente vinculados ao ideal moral da razão. Um convite ao pensamento como processo em movimento tendencial ao infinito. Aventura que quebra amarras e limites da representação impostos à natureza subversiva da diferença. Se a razão-moral, em sua estrutura lógica, opera eliminando a diferença como elemento que coloca em risco a ordem do pensar estabelecida como um a priori e se entendemos que a diferença, em sua radicalidade, pode aparecer como um movimento extremamente desestabilizador, provocando o aprofundamento do caos, cabe interpelar a moral em sua lógica de servidão ao modelo. Em nosso entender este seria o próprio pensamento como atividade criadora: um exercício de reparar, interpelar, abalar o modelo, expondo seu caráter contingente e precário e as forças que lhe dão sustentação, ao mesmo tempo que libera virtualidades e produção de diferença.

Considerar o pensamento e, portanto, a escrita como exercício criador, certamente nos coloca frente a um desafio sendo impossível não lembrar o papel ou a tela em branco, a angústia gerada e a insistente pergunta "como começar?". Numa entrevista concedida em 1984, Guattari comenta sobre o movimento criador recorrendo aos estudos da arte em Deleuze:

[...] o problema, para um pintor, quando está diante da tela em branco, é que a tela não é branca. Ela é habitada por uma virtualidade infinita de representações e é preciso, justamente, torná-la branca, fazer essa passagem de um vazio, que não está carregado energeticamente, mas sim carregado de formas, para reencontrar um ponto de emergência criacionista (UNO, 2016, p. 109).

Guattari sugere que não se trata de idealizar um ponto zero, um vazio inaugural, mas viver a tensão "entre a fixidez do ser e o infinito do incorporal" (Ibidem), entre a experimentação e a criação, como dobras do instituído. Nessa relação o infinito emerge como possibilidade instituinte. Acolhendo a imprevisibilidade e problematizando os modelos que estruturam nossa existência, podemos dar visibilidade a relações de incompletude dos processos de criação, invisibilizados ou recusados quando adotados formas e procedimentos pré-estabelecidos, tanto no exercício do pensar, quanto em suas diversas possibilidades de objetificação, como ocorre na prática da escrita. Perspectivar os modelos frente a modos de subjetivação normalizados é um jogo desestabilizador. Intervir, pesquisar e escrever deslocando-se dos modelos rompe os limites da técnica, dos propósitos cientificistas e da política de resultados, nos instalando em processos iminentes de experiências singulares, portadoras de devires. Assim, a escrita acadêmica além de registro de impressões e de expressões do que se recolhe nas práticas, será tomada como suporte e como acesso a um plano de experiência.

Esses deslocamentos e essas recomposições promovem desarranjos nas relações de saber-poder, ao mesmo tempo que nos implicam em processos de desaprendizagens das fórmulas que se oferecem como garantias à manutenção de domínios. Que tal não seja 
confundido com falta de rigor, pois este se apresenta na afirmação permanente do comum, enquanto plano coletivo transversal às práticas implicadas do fazer acadêmico.

Grande parte da produção acadêmica se dá por uma escrita submetida ao julgamento de pares. Nessa relação é validado ou refutado o trabalho, não só dos estudantes (com as produções que vão, do trabalho para uma disciplina curricular, à tese de doutorado), como de todo pesquisador que quer publicar, ter fundos para realizar um estudo, ganhar um prêmio ou concorrer a uma bolsa. É precípua a função normativa da escrita, que no dizer de Jorge Ramos do Ó (2019), se configura como um "governo do enunciável”, à medida que "[...] se vai afirmando muito mais enquanto instrumento da veridicção, ao serviço dos sucessivos poderes do tempo, do que como dispositivo de informação ou de dissecação, de análise ou de produção de novas interpretações e mundividências" (p. 98). Como campo das relações de poder, a prática instituída do escrever fala do governo da produção acadêmica.

Um desejo persistente entre pesquisadores é colocar em debate os pareceres desqualificadores que recebem para seus projetos e artigos submetidos a juris. Neles argumenta-se que não são adequados quanto ao modo de apresentá-los, à clareza dos objetivos, aos procedimentos técnicos escolhidos e aos referenciais analíticos. Para além do argumento de que os trabalhos "não são compreendidos" por falta de informações que poderiam ser supridas, pode-se pensar no trabalho que é considerado bem apresentado e sólido por alguns pares e, sob outro olhar, é declarado "sem objetivos", com "objetivos irrelevantes ou inconsistentes", com uma "metodologia não adequada", dentre outros argumentos desqualificadores ${ }^{3}$. Certamente há relações de poder institucionais atravessadas que falam de perseguições pessoais, mas não é esse o foco da presente análise, e sim pensar que mesmo sem nenhuma perseguição pessoal a leitura que se faz de um texto no campo acadêmico é atravessada por mecânicas de governo da escrita, que são mecânicas de governo do pensar.

A sacralização da escrita é construída nos albores da escola, como parte de um projeto de uniformização não dos textos, mas das vidas. Vida disciplinarizada, como entende Michel Foucault, lapidada com mecanismos que produzem obediência, padronização e serialização.

Contrariamente à ideia de que a ciência liberta das trevas, o que vemos consolidar-se no século XIX não deixa de ser a construção de um referencial único, para dar veracidade aos enunciados. Já não sob o domínio de um ser superior-místico, é difundido um caminho para a construção de verdade, agora ao alcance dos inteligentes e capazes. Constrói-se a certeza contida em um enunciado, porque inquestionável, sempre que apoiado no que se define como ciência. Esta é entendida por um escopo de procedimentos limitados e controlados, que todo trabalho deve seguir para ser certificado. De vários modos esse escopo se apresenta: passos a seguir em laboratórios, sumários que estruturam a escrita, técnicas pautadas em modelos, ações identificadas como os objetivos possíveis... Algumas cenas ajudam a entender e colocar em análises tais mecânicas:

Quando o sumário não atende a uma ordem prevista pelo saber da ciência em um campo específico tende-se a refutar a apresentação, argumentando ser um trabalho desordenado, sem sentido. Não por acaso, em geral, os editais para a apresentação de projetos ou trabalhos definem os itens que devem constar e a ordem em que devem ser expostos. Isto ocorre, por 
exemplo, com a apresentação institucional de pesquisas (sobretudo no caso em que são submetidas a concurso), sob o argumento da necessidade de uma padronização, na ilusão de serem submetidos a uma comparação "em igualdade de olhares". Não cabe a possibilidade de que cada pesquisa construa seus modos de falar e fazer-se ouvir, para além da estrutura clássica de "introdução, objetivos, metodologia (que é igualada a método), desenvolvimento, resultados, referências". Uma estrutura que define um modo de organizar, destacar, excluir, comprimir o conteúdo, sem abrir espaço para o diverso, para o que não existe a priori, e que deixa de "poder ser" na medida em que a pesquisa é engarrafada de antemão em um modelo que confere um status institucional.

Do mesmo modo, se alguma proposta indica ações que surpreendem o leitor/avaliador, ela é declarada "sem objetivo". Na década de 1990 um parecerista desconhecia o sentido de "problematizar" (objetivo que em 2020 é recorrente nas pesquisas institucionais) e declara não ser esta uma ação possível para um projeto de pesquisa. ${ }^{4}$ Retira-lhe o apoio. Do mesmo modo, "analisar as mecânicas de governo" de um campo de estudo específico foi considerado "vago" e reprovável, porque distante do olhar empírico e comportamental que exige nomear, de antemão, as mecânicas em questão frente às quais - já pré-estabelecidas - caberia à pesquisa descrevê-las. Exigência que subentende que se estuda o que se conhece; se aprofunda a ideia já instituída e legitimada, sem abrir possibilidades para possíveis mecânicas a serem descobertas com a investigação, o que significa invalidar uma perspectiva genealógica.

Como nomear o que não se conhece, mas se deseja conhecer em um movimento possível pela ideia de encontro? Inaceitável? Arriscado? Subjaz aos exemplos apresentados, uma concepção da pesquisa como atividade conduzida por uma estrutura dada, a ser explorada para melhor qualificar, sem alterar o pensamento que define o que é uma questão.

[...] meus livros são, para mim, experiências, em um sentido que gostaria o mais pleno possível. Uma experiência é qualquer coisa de que se sai transformado. Se eu tivesse de escrever um livro para comunicar o que já penso, antes de começar a escrevê-lo, não teria jamais a coragem de empreendê-lo. [...] Sou um experimentador no sentido em que escrevo para mudar a mim mesmo e não mais pensar na mesma coisa de antes (FOUCAULT, 2010, pp. 289-290).

A escrita de um texto acadêmico tem se assemelhado à reprodução de um código familiar, confortável, que reforça certos saberes como meio a fortalecer poderes, que não só falam da institucionalização do fazer educativo, mas de todas as relações que se apoiam nele para legitimar-se. Pode-se pensar que a perspectiva da crença em seu sentido devocional, assim como acontece com a religião, mantém-se objetificada já não em um ser todopoderoso, em uma deidade, mas em seres dotados de inteligência (por isso também superiores) e treinados de modo a aferir a condição de cientistas.

À tarefa do treino se dedicam as guias e os manuais metodológicos que explicam o passoa-passo para uma boa pesquisa, mesmo trabalhando-se com objetos, cenários, campos empíricos, recursos, afetos diversos. Essa a tarefa da maior parte dos cursos sobre 
metodologia científica, destinados a ensinar como pesquisar. A qualidade de organizar o pensamento não deixa de ser um mecanismo de imposição de uma ordem ao pensar, que leva a salientar algumas relações e a eliminar outras. Senão, vejamos: preocupado com o seu desempenho na disciplina "metodologia" do doutorado, um estudante leva à sua orientadora o enigma de colocar o seu projeto de pesquisa nos tópicos definidos pela professora da disciplina como aqueles que lhe dariam consistência e clareza. Naquela ordem discursiva proposta não caberia uma série de percursos da pesquisa ou talvez coubesse em mais de um item. Tratava-se de colocar o que se queria e o como se queria dizer em um roteiro prédefinido. Um roteiro que obrigava a deixar de lado muito do que se queria dizer e a dizer coisas que não teriam feito parte da construção do projeto se o esquema fosse outro. Percurso, esse, talvez incompreensível para quem não busca um modelo pré-estabelecido e, portanto, não cumpre com as exigências de uma disciplina que apresenta uma fôrma ("elástica") como condição para poder dialogar.

O modelo como elemento estruturante é naturalizado e dizer que ele pode ser elástico, flexível, adaptável (resiliente, como quer o discurso neoliberal) é a sua afirmação como referência central para a enunciação discursiva. Tal a atribuição do método científico, responsável, a partir do século XIX, por sagrar por novos meios a verdade única. Mais que afirmar verdades, o método universal desqualifica os discursos que fogem ao controle dos procedimentos definidos como científicos, exercendo coação sobre todos os outros modos de produzir saber. Não se trata de dizer a verdade, mas como afirma Foucault (1996), de estar na verdade por obedecer às regras discursivas. Modelos que sob a condição de científicos têm, como efeito mais agudo, invalidar referências e procedimentos diversos para pensar.

Em sua aula inaugural no Collège de France, Foucault (1996) sublinha que todo discurso é construído com "procedimentos de exclusão". Uma provocação a de pensar não nos elementos que estruturam um texto escrito, mas antes, o que interditamos ao formular nossos discursos, a que damos relevo ou, em seus termos, como classificamos, ordenamos e distribuímos os discursos. Olhar para o que ensinamos como passos de interdição é um modo de nos interrogarmos sobre a possibilidade de incentivarmos outros caminhos do pensar.

Sair de o método é o descentramento de uma estrutura e, como tal, da noção de totalidade na que se inscreve. Estrutura é uma noção que organiza e submete as ideias que a partir dela e em torno dela circulam, aprisionando o pensar nos limites do que se define como campo de possibilidade. Um modo de autorregulação, como propõe Piaget (1979); de controle do pensar e do sentir, pois traça um processo de pesquisa com limites dados pelos procedimentos. A própria ideia de neutralidade fundante do que podemos chamar de " $\mathrm{O}$ Império da Ciência" - o lugar da verdade deslocado das referências senhoriais - consolidada com a hegemonia do pensamento positivista no campo da produção do saber, centra o processo de pesquisa no sujeito: naquele a partir do qual se constrói o saber. Seja um sujeito que define um modelo que autoriza falar, sujeitando-se a um caminho para pesquisar, a um método, seja um sujeito que organiza o pensamento por meio de um a priori, naturalizando lugares e funções.

No primeiro caso, o procedimento padrão, correto, considerado consistente porque sustentado em etapas sob controle, opera como uma estrutura que toma o lugar de um sujeito 
identificado como científico, que outorga status de certeza ao que, por seu intermédio, é enunciado. No segundo caso, o objeto da pesquisa é um sujeito já codificado, classificado, justificado por uma identidade que assujeita o processo investigativo a uma essência a partir da qual se desdobram as análises. Um exemplo de tal codificação pode ser uma pesquisa sobre mães, partindo de uma concepção única de maternidade, ou as pesquisas sobre infração penal, que dispensam colocar em análise os conceitos que lhe são centrais, por naturalizar-se o que é uma mãe ou uma infração, sem dar espaço para que ambas sejam problematizadas como produções históricas. Sob tal ótica, a infração penal ou a maternidade não são um dado de realidade a descrever, mas relações políticas que têm potentes efeitos de dominação. Torná-las o sujeito da pesquisa faz com que o pesquisar se assujeite a olhares pré-definidos. Por outra via, pensar as relações como produções genealógicas desloca o pesquisar da perspectiva de assujeitamento por entender as relações como acontecimentos que nos convocam a historicizar e enfrentar os instituídos. Segundo Foucault (1995) os processos de assujeitamento estão engendrados nas relações sociais e é por meio deles que os indivíduos são normalizados e o sujeito se produz. Ou seja, estamos todos em um mesmo emaranhado de saber e de poder que condiciona nossa ação.

Desmanchar zonas de tensão e insegurança por meio de passos firmes e cuidadosos no trabalho investigativo é uma tarefa fundamental da orientação, pois a vida não é vivida de modo segmentado e não só as tensões particulares estão presentes no curso, como as tensões próprias a um trabalho de grande exigência, inclusive pelo enquadramento às rígidas normas institucionais, têm efeitos evidentes na vida diária dos estudantes. "Ao escrevermos, como evitar que escrevamos sobre aquilo que não sabemos ou que sabemos mal?", nos provoca Deleuze, insistindo em dizer que "só escrevemos na extremidade do nosso próprio saber, nesta ponta extrema que separa o nosso saber e nossa ignorância e que transforma um no outro" (Deleuze, 1988, p. 10).

A produção de uma pesquisa é a produção de si e os enquadramentos metodológicos expressos no trabalho escrito falam de uma produção de si subalternizada. A esses procedimentos servem as disciplinas: demarcações arbitrárias que direcionam as interconexões às quais uma realidade é submetida. Em ambas as situações a escrita por meio da qual se faz a pesquisa parte de uma estrutura central, assujeitando a produção a processos de interdição e controle. São procedimentos que outorgam um lugar de verdade, dominado por um modelo de escrever que se consolidou no século XIX, eliminando a curiosidade, a dúvida e a multiplicidade de ideias. "A esse trabalho permanente e perpétuo de remediar a divisão do corpo social por meio de uma escrita conforme à verdade deve dar-se, sem receio, o nome de pedagogia" (Ó, 2019, p. 107).

Entre as muitas funções conquistadas pelo trabalho pedagógico escolar, que se tornou um mecanismo universal de governo ao longo do século XIX e no início do século XX, está a naturalização da categoria sujeito, definido por uma estrutura do que se construiu como da ordem do humano. No contexto da consolidação do pensamento liberal, o século XIX instituiu o humanismo como modo de referir as relações sociais, colocando o sujeito no centro delas, como elemento estruturante: um sujeito íntimo, descolado das relações históricas, econômicas, éticas, culturais, que por suas características naturais é colocado no 
centro das relações sociais. Esse sujeito é produzido como o a-lumini (sem-luz), o aluno da escola, um meio para esculpir os novos modos de assujeitamento por mecanismos tais como a construção da escrita. Não é alguém que estuda - um estudante - mas aquele a quem há que iluminar com códigos normalizadores em termos do seu comportamento e, mais importante, de seu pensamento e seus afetos.

A escrita é transformada em uma técnica que emerge como fundamental à vida civilizada e, pouco a pouco, à inserção nas relações de trabalho, dizendo muito mais da composição de um sujeito modelado-dominado, que de um recurso de comunicação. Uma figura central à escrita acadêmica é a do autor como sujeito, que em um quadro normalizado propõe o texto, dando-lhe unidade e coerência, personificando a produção e, nesse movimento, destituindoa da sua dimensão coletiva. A boa escrita é a prova da competência individual, validando profissionalismo e talento.

Ensinar a escrever não é apenas uma operação técnica mas, antes, um modo de ordenar o pensamento. A estrutura de um texto conforme aprendida no processo de escolarização é a estrutura lógica com a que lemos o mundo. Partir do sujeito na escrita é organizar o pensamento em torno de uma estrutura íntima tendo, com ela, a ordem privada como centro das relações, como determinante das relações sociais.

Nossa disposição à experiência da escrita se inscreve e se alimenta numa miríade de questões emergentes em análises permanentes e localmente circunscritas a nossas práticas que, dentre outros efeitos, convergem para a instituição do sujeito da escrita, como eixo estruturante subjetivo, enquadrando as ideias em um modelo de existência e do pensar. Desse modo, entendemos que nos tornamos operadores de processos de formação que geram subjetivação, processos enredados com materialidades das dimensões institucional e cultural. Deslocar-se do sujeito como relação estruturante é uma operação filosófica, ética e política, por obrigar a olhar, como propõe Foucault (2005), para as condições da emergência de uma relação. Nada simples quando o humanismo coloca como centro das relações o sujeito como ordem discursiva.

\section{A escrita na imanência das relações de poder na universidade}

Como temos enfrentado os efeitos da normalização no âmbito acadêmico? Que lugar temos dado à escrita? E mais, de qual escrita falamos?

Algumas tensões presentes nas lutas pela democratização da universidade (acesso, transformação de valores e de institucionalidades) se apresentam hoje, frequentemente, sob a forma de impasse, nos levando a ter que considerar a política de alianças como um tema central ao enfrentamento aos desmontes em curso operados pelo programa fascista neoliberal. Em décadas passadas os ataques se impuseram a partir da criação de indicadores, da implantação de um sistema de avaliação de desempenho institucional, de ajustes nos critérios meritocráticos para o julgamento de apoios financeiros e de títulos, na direção da criação de centros de excelência, construindo argumentos e justificativas para privatizações diversas. O discurso da escrita e do conteúdo certos encobre o sentido político do que é 
legitimado como acadêmico, necessário, prioritário, apropriado, oportuno, urgente. Colocar em análise as armadilhas postas pelo discurso da escrita certa é um movimento acadêmico que faz emergir as forças que organizam um projeto que vai muito além das atividades rotineiras e internas das universidades. Hoje, a aliança estatal-empresarial além de cortes orçamentários, de bloqueio de bolsas, de interferências na posse de reitores, investe contra a liberdade de cátedra, pelo que procuram quebrar as perspectivas até então consideradas como críticas, na intenção de se reapropriarem dos sentidos de tais críticas, fazendo-as equivaler a julgamentos morais.

Nessas condições, manter o benefício da dúvida frente à exclusão e tentativa de criminalização de discursos e de posicionamentos políticos minoritários, sustentar um campo de tensão e o dissenso, esteios na gestão democrática dos processos de trabalho e de formação, implica assumir os riscos de um combate. Um combate que se inicia na análise de nossas próprias práticas, das condições criadas no "entre nós" que favorecem naturalizações acríticas e nos fazem potenciais agentes de capilarização dos controles. Captação de recursos, acesso a cursos e instituições, aprovação em eventos acadêmicos, entre tantas atividades cotidianas, consideradas banais na rotina de trabalho, falam de tal capilarização dos controles importantes de serem desmontados por meio de outros modos de gerir e viver a produção que se objetiva sobretudo por meio da escrita. Nessas condições, podemos dizer que chegamos hoje a uma tensão paradoxal de que o uso da crítica e das interpelações que endereçamos às instituições se tornem armas colocadas nas mãos do inimigo.

Pensamos, por exemplo, nas discussões que há tempos envolvem as ciências humanas e sociais nas análises sobre o distanciamento entre o que se produz como conhecimento e as condições de vida da maioria de nossa população, suas necessidades, os interesses dos movimentos sociais, quando boa parte do que se produz é feito em nome do que é melhor para a população. Como avançar nessa análise sem tornar a universidade ainda mais vulnerável aos ataques a ela hoje dirigidos? Nesse escopo interessa pensar os efeitos que tem a forma escrita na produção de políticas e dos efeitos delas nas condições sob as quais o trabalho acadêmico acontece.

A crítica se torna um desafio que comparece nas lutas por acesso e também, o que tem sido mais (in)tenso, nas reivindicações por condições de permanência daqueles que chegam, oriundos de experiências sociais nas quais a presença da escolarização - nos moldes instituídos nas políticas de educação - é mínima ou mesmo ausente (o que não quer dizer que populações consideradas periféricas não sejam afetadas pelo que a escola produz). As referidas condições de permanência envolvem uma variedade de necessidades, pontos de reivindicação, que transitam do apoio na forma de financiamento aos estudantes, até o questionamento e exigências de mudanças sobre as referências teórico-filosóficas, as estratégias de avaliação e os modos de expressão normatizados, reconhecidos e validados como acadêmicos.

$\mathrm{Na}$ condição de professoras universitárias, somos parte do coletivo docente que tem poder de incidência em alguns processos que podem contribuir para o fortalecimento das lutas estudantis. É frequente que a direção das lutas de estudantes e de docentes seja a mesma: a garantia de investimento e de sustentabilidade para uma universidade pública, laica e 
democrática. Tal direção, no entanto, não anula divergências ou mesmo antagonismos que, em alguns momentos, evidenciam nossas diferentes implicações, exigindo a análise do sistema de lugares instituídos, de nosso encargo social. Essa é sem dúvida uma importante dimensão a ser considerada em nossas análises, especialmente quando nos alinhamos ao entendimento de que a universidade não está fora dos processos de escolarização e, portanto, instrumentaliza instituições disciplinares e se faz campo de incidência biopolítica em todo processo pedagógico, para além do escolar.

Se a ordem disciplinar segue repartindo nossa formação social em campos de saberes, lugares especializados e seus correspondentes especialistas, as modulações biopolíticas intensificam a racionalidade governamental, investindo na condução de nossas vidas em suas diferentes dimensões (educação, natalidade, saúde, trabalho...). Cabe então considerar que a universidade, em sua dimensão jurídica e em suas práticas cotidianas é, também, aparelho de captura, compõe uma função normalizadora na maquínica da formação social. No entanto, o cotidiano de suas práticas nos interessa como plano no qual saber-poder e modos de subjetivação se processam em relações de forças e devires que, a depender dos agenciamentos, constrangem, enquadram, divergem, criam. A depender dos agenciamentos, do modo de produção da realidade, material e imaterial, tais processamentos (de)compõem modos de vida sendo, portanto, potencialmente geradores de novas práticas. Uma tal função maquínica, a de criação, não se faz do nada e nem espontaneamente, nos forçando a pensar que é necessário e urgente determinar suas condições de possibilidade, criar as condições para a criação e a sustentabilidade do que forjamos como modos dissidentes de subjetivação (UNO, 2016; DELEUZE; GUATTARI, 2016; LAZZARATO, 2006).

Nessa perspectiva, as mudanças desejadas por alguns no sentido da democratização das relações acadêmicas e aquelas reivindicadas por muitos que insistem na ampliação de modos dissidentes de subjetivação, com a inclusão de outros corpos, de outras narrativas, de outros mundos, se faz, para nós, numa atitude histórico-crítica radical. Uma atitude que vincula um pensar que interpela nossos pretensos objetos naturais

no vínculo possível entre um pensar que desnaturaliza radicalmente os pretensos objetos de nosso cotidiano e a possibilidade de constituir novas estratégias e táticas de ação que escapem - mesmo que provisoriamente - ao cientificismo, funcionalismo, individualismo, sexismo, especificismo e tecnicismo hegemônicos (RODRIGUES, 1994, p. 31).

O que se afirma, então, é uma prática crítica de recusa, transgressiva e situada. Podemos então retomar a conversa, já iniciada, sobre as condições de permanência na universidade e as interpelações que pedem mudanças nas referências teórico-filosóficas, na avaliação e nos modos de expressão normatizados, reconhecidos e validados como acadêmicos. A essas três peças-chave, encontradas em qualquer processo de formação, queremos nomear aqui como dispositivos analisadores que, em suas diferentes montagens, são operadoras de intervenção e de análise do referido processo. Na perspectiva de uma atitude histórico-crítica, fazemos um exercício de aproximação dos três eixos de uma ontologia histórica de nós mesmos, 
"remetendo à profunda relação das pesquisas foucaultianas com o presente; com um pensar a história (do ser e de nosso ser-sujeito) não como narrativa do superado, e sim na qualidade da arma nos combates do presente" (RODRIGUES, 1994, p. 28).

Foucault refere três domínios possíveis em seu projeto genealógico:

Primeiro, uma ontologia histórica de nós mesmos em relação à verdade através da qual constituímos a nós mesmos como sujeitos de saber; segundo, uma ontologia histórica de nós mesmos em relação a um campo de poder através do qual constituímos como sujeitos de ação sobre os outros; terceiro, uma ontologia histórica em relação à ética através da qual nos constituímos como sujeitos morais (DREYFUS; RABINOW, 1995, p. 262).

Entendendo que a escrita como problema delimita uma experiência que fala de "qualquer coisa de que se sai transformado" (FOUCAULT, 2010, p. 289) sugerimos destacar, nos processos de escolarização acadêmica, três vetores que nos abrem acessos a uma analítica da formação. Tais vetores, articulados no cotidiano das práticas, estabelecem um regime de saber-poder na instituição do sujeito da escrita. Assim, consideramos: a citação como procedimento que indica e valida nossa relação com a verdade; a avaliação como exercício que nos inscreve num campo de poder, e as formas de expressão - dentre as quais aqui destacamos a escrita - como matéria privilegiada para a análise da relação de si por si.

Tal analítica pode nos dar a ver modos de vinculação entre agentes (discentes, docentes) e entre estes e textualidades diversas - verbal (oral, escrita), visual e suas possíveis combinações. Poderiam ser, ainda, os elementos que se instrumentalizam na composição de dispositivos (artigos, livros, vídeos, transcrições, fotos, diários de campo...) que, nessa condição, também interferem, modificam, provocam agentes e textualidades, fazendo emergir virtualidades que se manifestam quando se instalam processos de criação.

A escrita, como a entendemos aqui, como suporte de processos criativos, pode ser uma potente ferramenta de recusa à pretensão de totalização do mundo e à sedimentação do pensamento representacional. Tal ocorre tanto no ato de escrever, quanto no percurso que o texto faz no encontro com seus leitores. Ou seja, a escrita criativa tem aptidão para o contágio, vai além das intenções do autor, cujo texto dele se desprega ao encontrar seus interessados que, com suas leituras, o reescrevem. Nesse sentido, cabe citar Fonseca, Nascimento e Maraschin (2012) quando destacam as multiplicidades virtuais do ato de escrever, nos convidando a produzir narrativas que valorizem

[...] uma estética, uma ética que se ligam à vida e ao compromisso de expandi-la através de gestos de autoria que, menos do que falarem de um sujeito personalógico e de um Eu identitário e compacto, posiciona o pesquisador como portador e executante de uma função-autor, pela qual se constitui o leitor, aquele outro que, pelas afecções, sensibilidades e contágios, também se torna produtor de sentidos (p. 12). 
Fugindo dos processos prescritivos, escrever e ler se consubstantivam. Leitor e escritor reescrevem ideias e sentidos em um fazer artesanal. Não só o escrever refere criação, pois sem o leitor a interpelar o texto, este perde a sua função coletiva irradiadora de afetos. Escrever, em um horizonte criativo, é um trabalho artesanal, milimétrico, desobediente aos cronômetros e estilos. Requer espaço próprio; tempo para se refazer, em um exercício de encontro com os percursos por meio dos quais se desenha o texto. Desenho inesgotável porque a escrita está sempre por se fazer e se fazendo, tanto no ato da criação expressa em letras, quanto no encontro do leitor com a obra em uma dimensão acontecimental.

Há portanto que olhar para a escrita académica como um puro exercício de experimentação, da tessitura de uma mundividência que se ergue e aos poucos se impõe aos regimes de pensamento do próprio investigador [pois que] escrevemos para que a escrita possa continuar, para sair das relações conhecidas, e portanto já confortáveis, que temos tido com a linguagem (Ó, 2017, p. 52).

\section{Notas:}

1. Trabalho realizado no contexto do convênio CAPES-Print.

2. Curso "Por uma escrita acadêmica anti-normativa e inventiva", oferecido pelo professor Jorge Ramos do Ó (da Universidade de Lisboa), no PPFH/Universidade do Estado do Rio de Janeiro, de 2 a 5 de setembro de 2020.

3. Tais foram as expressões apresentadas, em 03/11/2018, no parecer Ad Hoc do processo No. 409163/20180 , da área da Educação do CNPq (Conselho Nacional de Pesquisa).

4. Na década de 1990 o projeto de extensão do Programa PIVETES, do Departamento de Psicologia da UFF, é recusado pela Pró-Reitoria de Extensão sob o argumento de não se entender o que seria "problematizar". "Problematizar" as práticas dos profissionais de psicologia no Juizado da Infância e da Juventude, no estado do Rio de Janeiro, era o objetivo central do projeto. Cabe registrar que em diálogo com o setor responsável por emitir pareceres e conceder apoios o projeto e seu objetivo, tido como inadequado na avaliação dos experts, foi aceito. Foi necessário um trabalho explicativo e argumentativo para que isso ocorresse.

\section{Referências}

DELEUZE, G. Diferença e repetição. Tradução: Luiz Orlandi e Roberto Machado. Rio de Janeiro: Graal, 1988.

Crítica e clínica. Tradução: P. P. Pelbart. São Paulo: Ed. 34, 1997.

DELEUZE, G.; GUATTARI, F. Maio de 68 não ocorreu [2003]. In: DELEUZE, G. Dois regimes de loucos. Tradução: Guilherme Ivo. Ed. 34, 2016. pp. 245-248.

DELEUZE, G.; PARNET, C. Diálogos. São Paulo: Escuta, 1998.

DREYFUS, H.; RABINOW, P. Michel Foucault, uma trajetória filosófica. Tradução: Vera Porto Carreiro. Rio de Janeiro: Forense, 1995.

FONSECA, T. M. G.; NASCIMENTO, M. L.; MARASCHIN, C. Rumores discretos de um abecedário de pesquisa. In: FONSECA, T. M. G.; NASCIMENTO, M. L.; MARASCHIN, C. Pesquisar na diferença: um abecedário. Porto Alegre: Sulinas, 2012. 
FOUCAULT, M. O sujeito e o poder. In: DREYFUS, H.; RABINOW, P. Michel Foucault, uma trajetória

filosófica. Tradução: Vera Porto Carreiro. Rio de Janeiro: Forense, 1995. pp. 231-249. 1996.

A Ordem do Discurso. Tradução: Laura Fraga de Almeida Sampaio. São Paulo: Edições Loyola,

. Nietzsche, a genealogia, a história. In: FOUCAULT, M. Ditos e Escritos - Vol. II Arqueologia das ciências e história dos sistemas de pensamento. 2a ed. Manoel Barros da Mota (Org.). Rio de Janeiro: Forense, 2005. pp. 260-281. (Coleção Ditos e Escritos, Vol. II).

Conversa com Michel Foucault. In: FOUCAULT, M. Ditos e Escritos VI - Repensar a política. Rio de Janeiro: Forense Universitária, 2010. pp. 289-347.

LAPASSADE, G. Grupos, Organizações e Instituições [1974]. Rio de Janeiro: Francisco Alves, 1977.

LAZZARATO, M. As revoluções do capitalismo [2004]. Rio de Janeiro: Civilização Brasileira, 2006.

LOURAU, R. Implicação e sobreimplicação. In: ALTOÉ, S. (Org.) René Lourau: Analista institucional em tempo integral. São Paulo: HUCITEC, 2004. 186-198.

NIETZSCHE, F. W. A genealogia da moral. Tradução: Antonio Carlos Braga. São Paulo: Lafonte, 2017.

Ó, J. R. do. Em defesa da universidade: Autorreflexividade, dúvida radical e escrita do devir. Práticas da História, n. 4. Universidade de Lisboa, 2017, pp. 127-194. Disponível em: <http://www.praticasdahistoria.pt/issues/2017/4/06_PDH_04RamosdoO.pdf>. Acesso em: 20 ago. 2020.

Fazer a mão - por uma escrita inventiva na universidade. Lisboa: Edições do Saguão, 2019.

PIAGET, J. O estruturalismo. Tradução: Moacir Renato de Amorim. São Paulo: Ed. Difel, 1979.

RODRIGUES, H. C. Do "Psi" ao genealogista - algumas contribuições foucaultianas para a trans-formação. Cadernos de Psicologia, n. 2, Série Social e Institucional. Universidade do Estado do Rio de Janeiro. Instituto de Psicologia, 1994, pp. 25-40.

UNO, K. Guattari - confrontações. São Paulo: N-1 edições, 2016.

\section{Correspondência}

Estela Scheinvar: Socióloga. Dra. em Educação. Professora do Departamento de Educação da Faculdade de Formação de Professores e do Programa de Pós-graduação em Políticas Públicas e Formação Humana.

E-mail: estela@uerj.br

Katia Aguiar: Psicóloga, Educadora Popular. Dra. em Psicologia Social. Professora do Instituto de Psicologia Graduação e Pós-Graduação.

E-mail: katiafaguiarpsi@gmail.com

Maria Lívia do Nascimento: Doutora em Psicologia. Professora do Instituto de Psicologia. Graduação e PósGraduação.

E-mail: mlivianascimento@gmail.com

Texto publicado em Currículo sem Fronteiras com autorização dos autores. 